Supplemental Information for:

\title{
Morphologic design of silver-bearing sugar-based polymer nanoparticles for uroepithelial cell binding and antimicrobial delivery
}

\author{
Yue Song, ${ }^{\dagger}$ Mahmoud Elsabahy, ${ }^{\ddagger}, \dagger$ Christina A. Collins,, Sarosh Khan ${ }^{\dagger}$ Richen Li, ${ }^{\dagger}$ \\ Teri N. Hreha," Yidan Shen, ${ }^{\dagger}$ Yen-Nan Lin ${ }^{\dagger}, \#$, Rachel A. Letteri, ${ }^{\dagger}$ Lu Su, ${ }^{\dagger}$ Mei Dong, ${ }^{\dagger}$ Fuwu Zhang, ${ }^{\dagger}$ \\ David A. Hunstad,", $\perp$ * and Karen L. Wooleyt, *
}

\footnotetext{
${ }^{\dagger}$ Departments of Chemistry, Chemical Engineering, and Materials Science \& Engineering, Texas A\&M University, College Station, Texas 77842, USA

¥Science Academy, Badr University in Cairo, Badr City, Cairo 11829, Egypt

Departments of "Pediatrics and ${ }^{\perp}$ Molecular Microbiology, Washington University School of Medicine, St. Louis, Missouri 63110, USA

${ }^{\#}$ College of Medicine, Texas A\&M University, Bryan, Texas 77807, USA
}

${ }^{*}$ Corresponding authors:

dhunstad@wustl.edu

wooley@chem.tamu.edu 


\section{EXPERIMENTAL SECTION}

Materials. L-Lactide was purified by recrystallization from ethyl acetate. 1,5,7Triazabicyclo[4.4.0]dec-5-ene (TBD) was used as received from TCI America (Portland, OR). The azidereactive fluorescent label MB ${ }^{\mathrm{TM}} 488 \mathrm{DBCO}$ was purchased from Click Chemistry Tools LLC (Scottsdale, AZ). Dichloromethane (DCM) was dried through a solvent purification system (J. C. Meyer Solvent Systems, Inc., Laguna Beach, CA). Nanopure water $(18.2 \mathrm{M} \Omega \cdot \mathrm{cm})$ was acquired through a Milli-Q water filtration system from Millipore Corp (Burlington, MA). All other chemicals were purchased from SigmaAldrich (St. Louis, MO) and used without further purification unless otherwise noted. Spectra/Por dialysis membranes (12-14 kDa molecular weight cut-off, MWCO) were purchased from Spectrum Laboratories, Inc. (Rancho Dominguez, CA). Slide-A-Lyzer dialysis cassettes (10 kDa MWCO) were purchased from Pierce Biotechnology (Rockford, IL). Dulbecco's Modified Eagle's Medium (DMEM) and Roswell Park Memorial Institute (RPMI) 1640 medium were obtained from the American Type Culture Collection (ATCC; Manassas, VA), with media additives (fetal bovine serum, penicillin/streptomycin) purchased from SigmaAldrich (St. Louis, MO). Cell culture 96-well round-bottom plates were purchased from Corning Costar Co. (Corning, NY).

Characterization. ${ }^{1} \mathrm{H},{ }^{13} \mathrm{C}$, and DOSY NMR spectra were recorded on Varian $500 \mathrm{MHz}$ spectrometers, interfaced to a UNIX computer using VnmrJ software. Chemical shifts were referenced to solvent resonance signals. Fourier-transform infrared (FT-IR) spectra were recorded on an IR Prestige 21 system (Shimadzu Corp., Japan), equipped with an attenuated total reflectance (ATR) accessory, and analyzed using IRsolution v. 1.40 software. Size exclusion chromatography (SEC) with tetrahydrofuran (THF) elution was conducted on a Waters Chromatography (Milford, MA) system equipped with an isocratic pump (model 1515), a differential refractometer (model 2414), and a four-column set, including a $5 \mu \mathrm{m}$ Guard column $(50 \times 7.5 \mathrm{~mm})$, a PLgel $5 \mu \mathrm{m}$ Mixed C column $(300 \times 7.5 \mathrm{~mm}$, Agilent Technologies $)$ and two Styrage ${ }^{\circledR}$ columns (500 $\AA$ and $104 \AA, 300 \times 7.5 \mathrm{~mm}$, Waters Chromatography). The system was equilibrated at $40{ }^{\circ} \mathrm{C}$ in THF with the flow rate set to $1.0 \mathrm{~mL} / \mathrm{min}$. Data collection and analysis were performed with Waters Breeze ${ }^{\mathrm{TM}}$ software. Molar masses were determined relative to polystyrene standards (615-442800 Da) purchased from Polymer Laboratories (Amherst, MA). Polymer solutions were prepared at a concentration of ca. $3 \mathrm{mg} / \mathrm{mL}$ with ca. 0.05 vol\% toluene added as a flow marker, and an 
injection volume of $200 \mu \mathrm{L}$ was used. Thermogravimetric analysis (TGA) was performed under an $\mathrm{Ar}$ atmosphere using a Mettler-Toledo (Columbus, $\mathrm{OH}$ ) model TGA2/1100/464 with a heating rate of 10 ${ }^{\circ} \mathrm{C} / \mathrm{min}$. Data were analyzed using Mettler-Toledo STAR ${ }^{\mathrm{e}}$ v. 15.00a software. Glass transitions $\left(T_{\mathrm{g}}\right)$ were measured by differential scanning calorimetry (DSC) on a Mettler-Toledo DSC3/700/1190 ${ }^{\circledR}$ under $\mathrm{N}_{2(\mathrm{~g}) \text {. }}$ Measurements were performed with heating and cooling rates of $10{ }^{\circ} \mathrm{C} / \mathrm{min}$ and analyzed using MettlerToledo Stare v. 15.00a software. The $T_{\mathrm{g}}$ was taken as the midpoint of the inflection tangent of the third heating scan. Elemental analysis was performed at Midwest Microlab, LLC (Indianapolis, IN). Transmission electron microscopy (TEM) images were collected on a JEOL 1200EX operating at $100 \mathrm{kV}$ and micrographs were recorded at calibrated magnifications using an SIA-15C CCD camera. The samples as aqueous solutions $(8 \mu \mathrm{L})$ were deposited onto carbon-coated copper grids. Excess sample was wicked off using filter paper, and the grids were allowed to dry in air for $1 \mathrm{~min}$. Where indicated, grids were stained with $8 \mu \mathrm{L}$ of a $1 \%$ phosphotungstic acid (PTA) aqueous solution. After $30 \mathrm{~s}$, excess stain solution was quickly wicked off using a piece of filter paper, and the samples were left to dry under ambient conditions prior to imaging. Ultraviolet-visible (UV-vis) spectroscopy measurements were performed on a Shimadzu UV-2550 spectrophotometer. Fluorescence spectroscopy was performed on a Shimadzu RF-5301pc Spectrofluorophotometer. Confocal images were collected with an LSM 880 Airyscan confocal microscope (Carl Zeiss, Thornwood, NY). Minimum inhibitory concentration (MIC) assays were read on a Synergy 2 microplate reader (Bio-Tek, Winooski, VT). All experiments were performed according to the Environmental Health and Safety guidelines of Texas A\&M University and Washington University. Experiments involving mouse-derived cell lines (RAW 264.7) and HTB-9 human bladder carcinoma cell lines were performed according to guidelines provided by Texas A\&M's Institutional Biosafety Committee for biosafety level 1 organisms (Protocol Approval Number IBC2014-075). Dynamic light scattering (DLS) measurements were conducted using a Zetasizer Nano ZS instrument (Malvern Panalytical Ltd., Malvern, UK) equipped with a laser diode operating at $632.8 \mathrm{~nm}$. Scattered light was detected at $175^{\circ}$ and analyzed using a log correlator for a $0.5 \mathrm{~mL}$ sample in a disposable cell (capacity $=0.9 \mathrm{~mL}$ ). The photomultiplier aperture and attenuator were adjusted automatically. The particle size distribution and distribution averages were calculated using particle size distribution analysis routines in Zetasizer 7.13 software. Number of accumulations and measurement duration were adjusted automatically. All measurements were repeated three times. The 
average diameter of the particles is reported as the intensity-, volume-, and number-average particle diameter from three measurements. The zeta potentials of the nanoparticles were determined by electrophoretic light scattering using a Zetasizer Nano ZS instrument (Malvern Panalytical Ltd., Malvern, UK) equipped with a laser diode operating at $632.8 \mathrm{~nm}$. The zeta potential of the particles in suspension was obtained by measuring the electrophoretic mobility of the charged particles. Scattered light was detected at a $12.8^{\circ}$ angle at $25^{\circ} \mathrm{C}$. The zeta potential is reported as the average and standard deviation of three measurements.

Synthesis of $\mathbf{N}_{3}$-PDGC-b-PLLA. A solution in anhydrous dichloromethane (DCM) of propargylcontaining D-glucose carbonate monomer $(201 \mathrm{mg}, 0.535 \mathrm{mmol})$ and 3-azido-1-propanol $(0.10 \mathrm{~mL}, 9.8$ $\mathrm{mg} / \mathrm{mL}$ in DCM, $0.011 \mathrm{mmol}$ ) was prepared, and transferred to a vial equipped with a stir bar and a rubber septum in an argon-filled glovebox. The vial was then removed from the glovebox and connected to a Schlenk line. A solution of TBD in DCM $(0.1 \mathrm{~mL}, 13.5 \mathrm{mg} / \mathrm{mL}, 0.012 \mathrm{mmol})$ was injected quickly into the vial at $-78{ }^{\circ} \mathrm{C}$. After stirring for $10 \mathrm{~min}$, the reaction vial was taken out of the $-78{ }^{\circ} \mathrm{C}$ dry ice bath, and a solution of L-lactide $(77 \mathrm{mg}, 0.54 \mathrm{mmol})$ in DCM $(1.0 \mathrm{~mL})$ was added via syringe to the reaction mixture. The reaction was stirred for an additional $3 \mathrm{~min}$ at $\mathrm{ca} .0^{\circ} \mathrm{C}$ and then quenched by addition of excess acetic acid. Size-exclusion chromatography (SEC) of the crude product showed negligible peak at 27-28 min, indicating quantitative conversions of both monomers. Precipitation from DCM into methanol three times, and drying under vacuum yielded 1, $\mathrm{N}_{3}-\mathrm{PDGC}_{47}-b-\mathrm{PLLA}_{44}$ as a white powder. Yield: $215 \mathrm{mg}, 78 \%$. ${ }^{1} \mathrm{H}$ $\operatorname{NMR}\left(500 \mathrm{MHz}, \mathrm{CDCl}_{3}\right): \delta 5.36$ (t, $\left.J=10 \mathrm{~Hz}\right), 5.16$ (q, $\left.J=7 \mathrm{~Hz}\right), 5.03$ (d, J = $\left.4 \mathrm{~Hz}\right), 4.89$ (t, J = $\left.10 \mathrm{~Hz}\right), 4.79$ - $4.66(\mathrm{~m}), 4.30-4.26(\mathrm{~m}), 4.19$ (tt, $J=7,3 \mathrm{~Hz}), 4.01$ (d, J=10 Hz), 3.44 (s), 2.59 (q, J = $3 \mathrm{~Hz}), 1.95$ (p, J $=7 \mathrm{~Hz}), 1.58(\mathrm{~d}, J=7 \mathrm{~Hz}), 1.30(\mathrm{t}, J=7 \mathrm{~Hz}) \mathrm{ppm} .{ }^{13} \mathrm{C} \mathrm{NMR}\left(126 \mathrm{MHz}, \mathrm{CDCl}_{3}\right): \delta$ 169.76, 154.18, 154.19, 153.79, 153.69, 96.56, 77.07, 76.34, 74.28, 73.64, 72.34, 69.15, 66.78, 65.83, 64.93, 56.04, 55.91, 16.79, 14.27 ppm. FT-IR: 3286, 2978, 2106, 1751, 1450, 1373, 1234, 1195, 1118, 1087, 1018, 987, 910, 879, $779,663 \mathrm{~cm}^{-1}$. SEC (THF): $M_{\mathrm{n}}=16.8 \mathrm{kDa}, \oplus=1.09 . T_{\mathrm{g}}=110^{\circ} \mathrm{C}$. TGA in Ar: $250-390{ }^{\circ} \mathrm{C}, 75 \%$ mass loss; $20 \%$ mass remaining at $500^{\circ} \mathrm{C}$.

General procedures for thiol-yne click reaction with cysteine. A solution of $\mathrm{N}_{3}-\mathrm{PDGC}_{47}-b-$ PLLA44 (50 mg, 0.098 mmol alkyne), L-cysteine (160 mg, $1.3 \mathrm{mmol}), \mathrm{HCl}(0.5 \mathrm{~mL}$ ) and 2,2-dimethoxy-2phenylacetophenone (DMPA; $10 \mathrm{mg}, 0.04 \mathrm{mmol}$ ) was prepared in $5 \mathrm{~mL}$ of $\mathrm{N}, \mathrm{N}$-dimethylformamide (DMF), 
deoxygenated with bubbling $\mathrm{N}_{2(\mathrm{~g})}$ for $5 \mathrm{~min}$, and irradiated at $365 \mathrm{~nm}\left(1000 \mu \mathrm{J} / \mathrm{cm}^{2}\right)$ for $2 \mathrm{~h}$. The DMF solution was transferred into dialysis tubing (MWCO 12-14 kDa) and dialyzed against nanopure water adjusted to $\mathrm{pH} 3$ with $\mathrm{HCl}$ at $4{ }^{\circ} \mathrm{C}$ for $2 \mathrm{~d}$. The resulting solution was then lyophilized to yield the cysteinemodified polymer 2, $\mathrm{N}_{3}-\mathrm{PDGC}(\mathrm{cys})_{47-}-\mathrm{b}-\mathrm{PLLA} 44$ as a white solid. Yield: $88 \%$. ${ }^{1} \mathrm{H}$ NMR $(500 \mathrm{MHz}$, DMSO$\left.d_{6}\right): \delta 5.19$ (q, $J=7 \mathrm{~Hz}$ ), 5.14 (s), 4.98 (s), 4.84 (br), 4.43 (br), 4.15 (br), 4.00 (br), 3.81 (br), 3.70 (br), 3.08 (s), 2.90 (b), 2.75 (br), 1.46 (d, $J=7 \mathrm{~Hz}), 1.21$ (t, $J=7 \mathrm{~Hz}$ ) ppm. ${ }^{13} \mathrm{C}$ NMR (126 MHz, DMSO- $\left.d_{6}\right): \delta$ 169.46, 169.21, 153.83, 153.52, 118.90, 68.69, 64.65, 54.92, 52.21, 51.78, 40.43, 16.47, 13.99 ppm. FT-IR: 3680$2180,1750,1620,1480,1390,1245,1100,1020,880,770,630 \mathrm{~cm}^{-1} . T_{\mathrm{g}}=113^{\circ} \mathrm{C}$. TGA in Ar: $150-190$ ${ }^{\circ} \mathrm{C}, 20 \%$ mass loss; $190-370{ }^{\circ} \mathrm{C}, 40 \%$ mass loss; $20 \%$ mass remaining at $500{ }^{\circ} \mathrm{C}$.

\section{General procedures for preparation of $\mathrm{MB}^{\mathrm{TM}} 488$ DBCO labeled amphiphilic block}

copolymers. A solution of $\mathrm{N}_{3}-\mathrm{PDGC}\left(\right.$ cys) $47-b-\mathrm{PLLA}_{44}(15 \mathrm{mg}, 0.42 \mu \mathrm{mol})$ was prepared by first dispersing polymers in $1 \mathrm{~mL}$ of water and followed by adding ca. $10 \mathrm{~mL}$ of DMSO. MB TM $488 \mathrm{DBCO}(1.25 \mathrm{mg} / \mathrm{mL}$, $500 \mu \mathrm{L}, \mathrm{DMSO}$ ) was then added to the solution, and the reaction mixture was allowed to stir at room temperature shielded from light for $30 \mathrm{~h}$, followed by dialysis against nanopure water for $4 \mathrm{~d}$ to remove unconjugated dyes, yielding dye-labeled polymer solutions with a final concentration of ca. $0.2 \mathrm{mg} / \mathrm{mL}, 20$ $\mathrm{mL}$. The resulting solution was then lyophilized to yield the dye-labeled polymer 3, dye-PDGC(cys) $47-b$ PLLA44, as a fluffy orange solid. Yield: 93\%. ${ }^{1} \mathrm{H}$ NMR (500 MHz, DMSO-d $d_{6}+$ TFA-d): $\delta 9.79$ (br), 8.60 (s), 8.07 (s), $7.27(\mathrm{q}, J=7 \mathrm{~Hz}), 7.19(\mathrm{~m}), 7.00(\mathrm{~d}, J=8 \mathrm{~Hz}), 6.63(\mathrm{~d}, J=8 \mathrm{~Hz}), 5.20$ (q, $J=7 \mathrm{~Hz}), 5.13(\mathrm{~m}), 5.03$ (m), 4.88 (br), 4.80 (br), 4.50 (br), 4.21 (br), $4.13(\mathrm{br}), 4.01(\mathrm{~m}), 3.83(\mathrm{br}), 3.36(\mathrm{br}), 3.08$ (br), $2.89(\mathrm{~b}), 2.76$ (br), 1.46 (d, $J=7 \mathrm{~Hz}), 1.21$ (m) ppm. ${ }^{13} \mathrm{C}$ NMR (126 MHz, DMSO-d + + TFA-d): $\delta$ 169.75, 169.63, 169.46, 169.21, 153.82, 119.23, 113.34, 95.96, 80.32, 68.69, 65.84, 55.24, 55.00, 52.18, 40.43, 16.64, 14.17 ppm. FT-IR: 3681-2154, 1753, 1622, 1492, 1452, 1382, 1242, 1091, 1031, 981, 881, 780, $640 \mathrm{~cm}^{-1} . T_{\mathrm{g}}=105$ ${ }^{\circ} \mathrm{C}$. TGA in $\operatorname{Ar}: 150-200{ }^{\circ} \mathrm{C}, 20 \%$ mass loss; $200-340,32 \%$ mass loss; $25 \%$ mass remaining at $500{ }^{\circ} \mathrm{C}$.

Self-assembly of PDGC(cys)-b-PLLA. Three polymer 2 samples $N_{3}$-PDGC(cys)- $b$-PLLA were dissolved in nanopure water $(0.05-0.1 \mathrm{mg} / \mathrm{mL})$. The solutions were heated to $65{ }^{\circ} \mathrm{C}$ for $30 \mathrm{~h}$, and then allowed to cool to room temperature prior to characterizations and further experiments. For preparation of dye-containing nanostructures, the three polymer 2 samples N3-PDGC(cys)-b-PLLA were allowed to react 
with ca. $20 \mathrm{~mol} \% \mathrm{MB}^{\mathrm{TM}} 488 \mathrm{DBCO}$ and purified to yield fluorescent dye-labeled polymer, followed by the CDSA process.

Flow cytometry. 5637 bladder epithelial cells (ATCC HTB-9) were grown to confluence at $37^{\circ} \mathrm{C}$, $5 \% \mathrm{CO}_{2}$. Cells were liberated with trypsin/EDTA (Millipore Sigma, St. Louis, MO) and transferred to FACS tubes. Cells were washed with $2 \mathrm{~mL}$ of RPMI medium with $10 \%$ FBS and centrifuged gently for 5 min, then resuspended with NP preparations $(20-50 \mu \mathrm{g} / \mathrm{mL}$ polymer in RPMI with $10 \%$ FBS). Cells were incubated at $37^{\circ} \mathrm{C}$ rocking for $1 \mathrm{~h}$, then washed with FACS buffer, centrifuged at $1500 \mathrm{rpm}$ for $5 \mathrm{~min}$, and fixed with $3 \%$ paraformaldehyde (PFA) for $30 \mathrm{~min}$ at room temperature. After a final FACS buffer wash and centrifugation, cell pellets were resuspended in FACS buffer and filtered through 44- $\mu \mathrm{m}$ nylon mesh. Samples were analyzed on a BD LSR Fortessa X-20 using the blue 488-nm laser and 530/30 filter.

Cell internalization. 5637 bladder epithelial cells were plated at $5 \times 10^{4}$ cells per well in a 24 -well plate and grown overnight at $37^{\circ} \mathrm{C}, 5 \% \mathrm{CO}_{2}$. The following day, cells were washed with PBS, overlaid with fresh RPMI with $10 \%$ FBS containing NPs $\left(20 \mu \mathrm{g} / \mathrm{mL}\right.$ polymer), and incubated at $37^{\circ} \mathrm{C}, 5 \% \mathrm{CO}_{2}$ for $1 \mathrm{~h}$. Cells were washed thrice with PBS, then liberated with trypsin/EDTA, quenched with medium, and transferred to $1.5 \mathrm{~mL}$ tubes, then centrifuged at $3500 \times g$ for $4 \mathrm{~min}$. The pellet was resuspended in $3 \%$ PFA and fixed for $10 \mathrm{~min}$ at room temperature. After PBS washing and centrifugation, the cell pellet was resuspended in WGA 594 (Invitrogen, 1:5000 in PBS) and incubated for $3 \mathrm{~min}$ at room temperature in the dark. After PBS washing, centrifugation, and resuspension in PBS, cells were centrifuged onto poly(Llysine)-coated glass slides (CytoPro, ELITech Biomedical Systems). Coverslips were mounted using ProLong Gold antifade reagent (Invitrogen).

Cytotoxicity assays. 5637 bladder epithelial cells $\left(5 \times 10^{4}\right.$ cells/well $)$ were plated in 96 -well plate in RPMI 1640 medium (with 10\% fetal bovine serum [FBS] and 1\% penicillin/streptomycin). Cells were incubated at $37{ }^{\circ} \mathrm{C}$ in a humidified atmosphere containing $5 \% \mathrm{CO}_{2}$ for $24 \mathrm{~h}$. The culture medium was replaced by $100 \mu \mathrm{L}$ of serial dilutions of the polymers in fresh medium (final concentrations ranged from 1.5-210 $\mu \mathrm{g} / \mathrm{mL}$ ). The cells were incubated with the NP formulations for $72 \mathrm{~h}$; medium was then replaced with $100 \mu \mathrm{L}$ of fresh medium prior to the addition of $20 \mu \mathrm{L}$ of MTS combined reagent to each well (Cell Titer $96 ®$ Aqueous Non-Radioactive Cell Proliferation Assay, Promega, Madison, WI). After further incubation 
for $2 \mathrm{~h}$ in the dark, absorbance at $490 \mathrm{~nm}$ was measured using a SpectraMax M5 instrument (Molecular Devices, Sunnyvale, CA). Cell viability was calculated based on absorbance relative to control untreated cells. The $0 \%$ and $100 \%$ cell viabilities were represented by control medium (no cells) and cells with no treatment, respectively.

Immunotoxicity and anti-biofouling assessment of polymer nanostructures. Zwitterionic $\mathrm{N}_{3}-$ PDGC(cys) $70-b-P L L A_{18}, \quad N_{3}-P D G C\left(\right.$ cys) ${ }_{47}-b-$ PLLA $_{44}, \quad \mathrm{~N}_{3}$-PDGC(cys) $39-b-$ PLLA $_{74}, \quad$ anionic $\quad \mathrm{N}_{3-}$ PDGC(COOH $)_{47-} b-P L L A_{44}$, and neutral PEGylated $N_{3}-P D G C(P E G)_{47}-b-P L L A_{44}$ diblock copolymers were dissolved in autoclaved, $0.2-\mu \mathrm{m}$ filtered nuclease-free water at predetermined concentrations. The zwitterionic polymer solutions were heated at $65^{\circ} \mathrm{C}$ for $30 \mathrm{~h}$, followed by cooling to room temperature before use. All samples were adjusted to have a final concentration of $5 \mu \mathrm{g} / \mathrm{mL}$. RAW 264.7 mouse macrophages $\left(2 \times 10^{4}\right.$ cells/well) were plated in a 96 -well plate in DMEM with $10 \%$ fetal bovine serum and $1 \%$ penicillin/streptomycin and incubated at $37^{\circ} \mathrm{C}$ with $5 \% \mathrm{CO}_{2}$ for $24 \mathrm{~h}$. The medium was then replaced with fresh medium $1 \mathrm{~h}$ prior to the addition of $20 \mu \mathrm{L}$ of each of the samples. After a $24 \mathrm{~h}$ incubation, the supernatants were collected and centrifuged for $10 \mathrm{~min}$ at $13000 \mathrm{rpm}$. The expression of 23 mouse

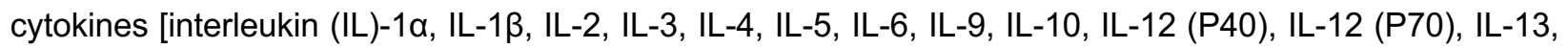
IL-17, eotaxin, granulocyte-colony-stimulating factor (G-CSF), granulocyte macrophage-colony stimulating factor (GM-CSF), interferon- $($ (IFN-ץ), keratinocyte-derived chemokine $(\mathrm{KC})$, monocyte chemotactic protein (MCP)-1, macrophage inflammatory protein (MIP)-1 $\alpha$, MIP-1 $\beta$, regulated upon activation normal T-cell expressed and presumably secreted (RANTES) and tumor necrosis factor- $\alpha$ (TNF- $\alpha$ )] were measured immediately using a BioPlex 200 system, equipped with high-throughput fluidics (HTF) and a Pro II Wash station, and data were analyzed using BioPlex Data Pro software. Expression data upon treatment with NP formulations were compared to those in control (untreated) cells. Adsorption of cytokines onto $\mathrm{N}_{3}$ PDGC(cys)-b-PLLA NPs of different morphologies and comparator NPs was calculated based on the apparent concentration of the cytokines measured after incubation with NPs, as compared to their concentrations in samples subject to the same procedures without NPs, as previously described. ${ }^{38-39}$

General procedure for the preparation of AgOAc-loaded polymeric NPs. A solution of AgOAc $\left(60 \mu \mathrm{L}, 4 \mathrm{mg} / \mathrm{mL}\right.$ in nanopure water) was added dropwise to a solution of polymer assemblies of $\mathrm{N}_{3}$ PDGC(cys)- $b$-PLLA $(0.57 \mathrm{mg}$, polymer concentration $=0.1 \mathrm{mg} / \mathrm{mL})$. The solution was shielded from light 
and allowed to stir overnight at room temperature to minimize light-induced reduction of $\mathrm{Ag}^{+} .45$ Unbound AgOAc was removed by centrifugal filtration (MWCO $30 \mathrm{kDa}$ ) several times $(N>3)$. The resulting solution of Ag@polymer micelles was reconstituted to a final volume of ca. $3 \mathrm{~mL}$, and the silver concentration was determined by ICP-MS. Aliquots of the solution of Ag@polymer micelles were used for TEM characterization. The zeta potential for Ag-loaded nanoparticles: Ag@spheres: $\quad-49.3 \pm 0.8 \mathrm{mV}$; Ag@cylinders: $-42.3 \pm 1.5 \mathrm{mV}$; Ag@platelets: $-44.7 \pm 2.5 \mathrm{mV}$.

Silver release. Solutions of silver-loaded $N_{3}$-PDGC(cys)-b-PLLA (3 mL) were transferred into presoaked dialysis cassettes (Slide-A-Lyzer, 10 kDa MWCO, Pierce Biotechnology, Rockford, IL). The dialysis cassettes were incubated in phosphate buffer $(10 \mathrm{mM}, \mathrm{pH} 7.4)$ with $10 \mathrm{mM} \mathrm{NaCl}$ at $37^{\circ} \mathrm{C}$ for $5 \mathrm{~d}$. Aliquots (ca. $0.1 \mathrm{~mL}$ ) from inside of the dialysis cassettes were extracted at predetermined intervals, and $\left[\mathrm{Ag}^{+}\right]$was measured by ICP-MS. Final results were obtained from triplicate experiments.

Antimicrobial activity. E. coli strains UTI89 and MG1655 were cultured in Luria-Bertani broth overnight at $37^{\circ} \mathrm{C}$. Strains were then subcultured into Mueller-Hinton broth and incubated with shaking at $37{ }^{\circ} \mathrm{C}$ until $\mathrm{OD}_{600 \mathrm{~nm}}=0.4$. Silver-bearing NP preparations were serially diluted in a 96-well plate to yield $\left[\mathrm{Ag}^{+}\right]=0.125-4 \mu \mathrm{g} / \mathrm{mL}$; then bacteria were added at $2 \times 10^{4}$ colony-forming units per well. Plates were incubated statically at $37^{\circ} \mathrm{C}$ in the dark for $24 \mathrm{~h}$, and $\mathrm{OD}_{600 \mathrm{~nm}}$ was recorded to determine bacterial growth vs inhibition. 
Table S1. Characterization of $\mathrm{N}_{3}$-PDGC-b-PLLA diblock copolymers.

\begin{tabular}{lcccc}
\hline & $\begin{array}{c}\mathrm{Mn}_{\mathrm{nNMR}} \mathrm{N}^{\mathrm{a}} \\
(\mathrm{kDa})\end{array}$ & $\begin{array}{c}\mathrm{Mn}_{\mathrm{n}, \mathrm{SEC}^{\mathrm{b}}} \\
(\mathrm{kDa})\end{array}$ & $\Xi^{\mathrm{b}}$ & $\begin{array}{c}\text { Nanoparticle morphology after } \\
\text { thiol-yne reaction and assembly }\end{array}$ \\
\hline $\mathrm{N}_{3}-\mathrm{PDGC}_{70}-b-\mathrm{PLLA}_{18}$ & 28.7 & 19.0 & 1.12 & Sphere \\
$\mathrm{N}_{3}-\mathrm{PDGC}_{47}-b-\mathrm{PLLA}_{44}$ & 23.9 & 16.8 & 1.09 & Cylinder \\
$\mathrm{N}_{3}-\mathrm{PDGC}_{39}-b-\mathrm{PLLA}_{74}$ & 25.2 & 17.9 & 1.21 & Platelet \\
\hline
\end{tabular}

a Determined by ${ }^{1} \mathrm{H} \mathrm{NMR}(500 \mathrm{MHz})$ in $\mathrm{CDCl}_{3}$.

${ }^{\mathrm{b}}$ Estimated relative to polystyrene standards by SEC eluting in THF.

${ }^{\mathrm{c}}$ After crystallization-driven self-assembly in nanopure water.
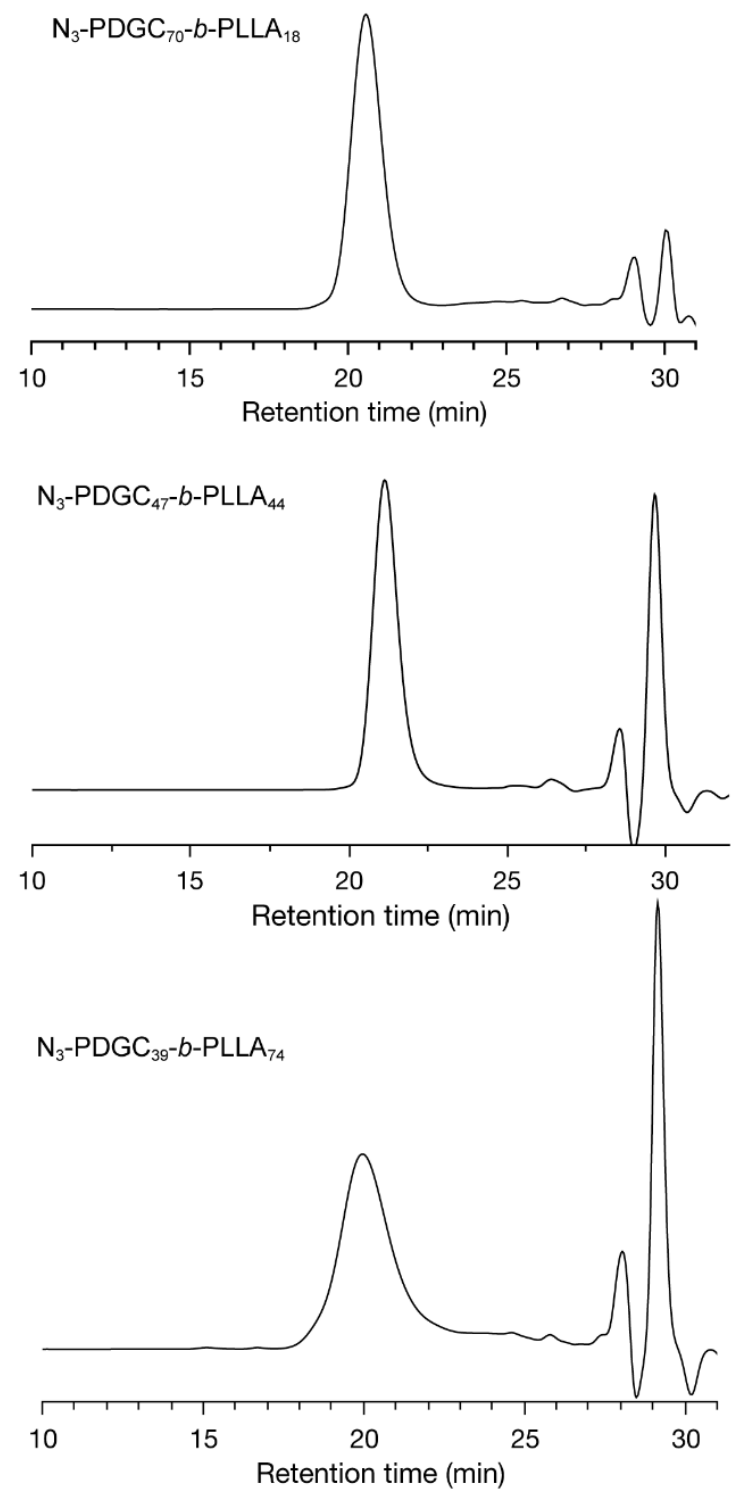

Figure S1. SEC chromatograms of $\mathrm{N}_{3}-\mathrm{PDGC}-b$-PLLAs. 
a

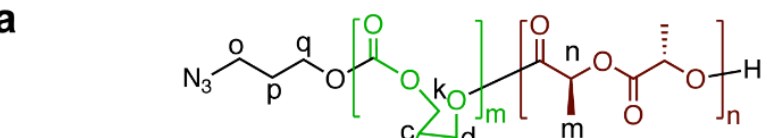
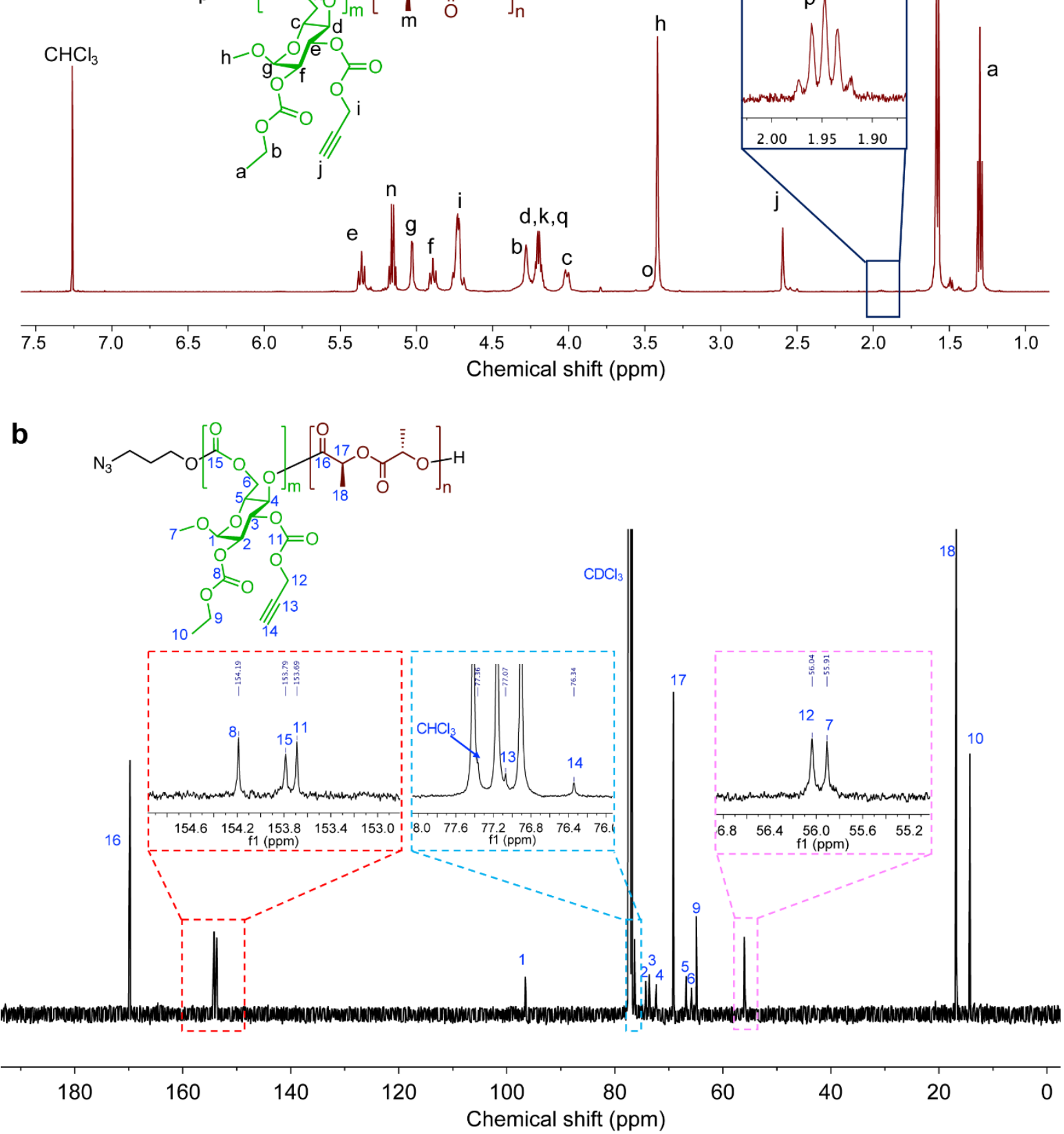

Figure S2. (a) ${ }^{1} \mathrm{H}(500 \mathrm{MHz})$ and (b) ${ }^{13} \mathrm{C}$ NMR (126 MHz, CDCl 3 ) spectra of 1, $\mathrm{N}_{3}$-PDGC-b-PLLA (sample $\left.\mathrm{N}_{3}-\mathrm{PDGC}_{39}-b-\mathrm{PLLA}_{74}\right)$. 

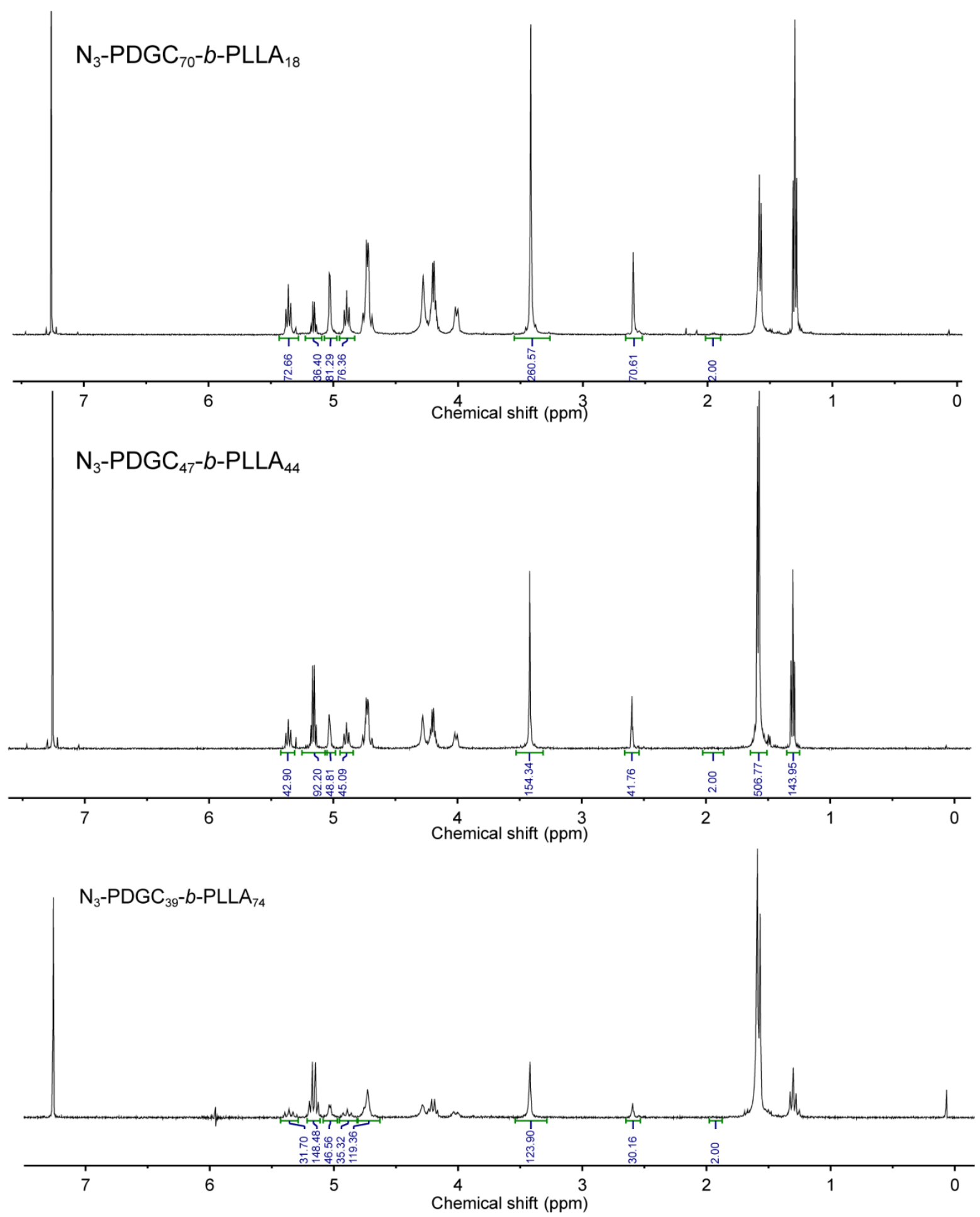

Figure S3. ${ }^{1} \mathrm{H}$ NMR integrations of all three $\mathrm{N}_{3}$-PDGC-b-PLLA polymers. 


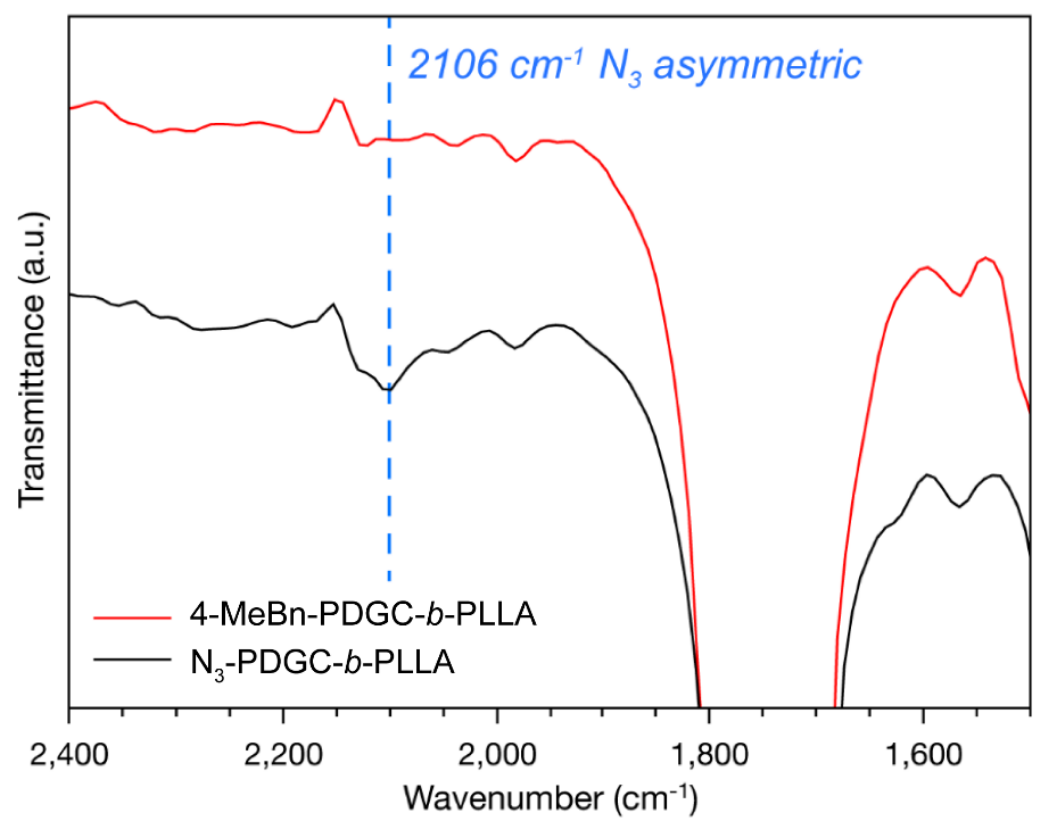

Figure S4. FT-IR spectra of PDGC-b-PLLA prepared by initiation with 4-methylbenzyl alcohol and 3-azidopropa-1-ol to afford PDGC-b-PLLA with a 4-methylbenzyl alcohol chain end (red line) and N3-PDGC- $b$ PLLA with a 3-azido-propa-1-ol chain end (black line).

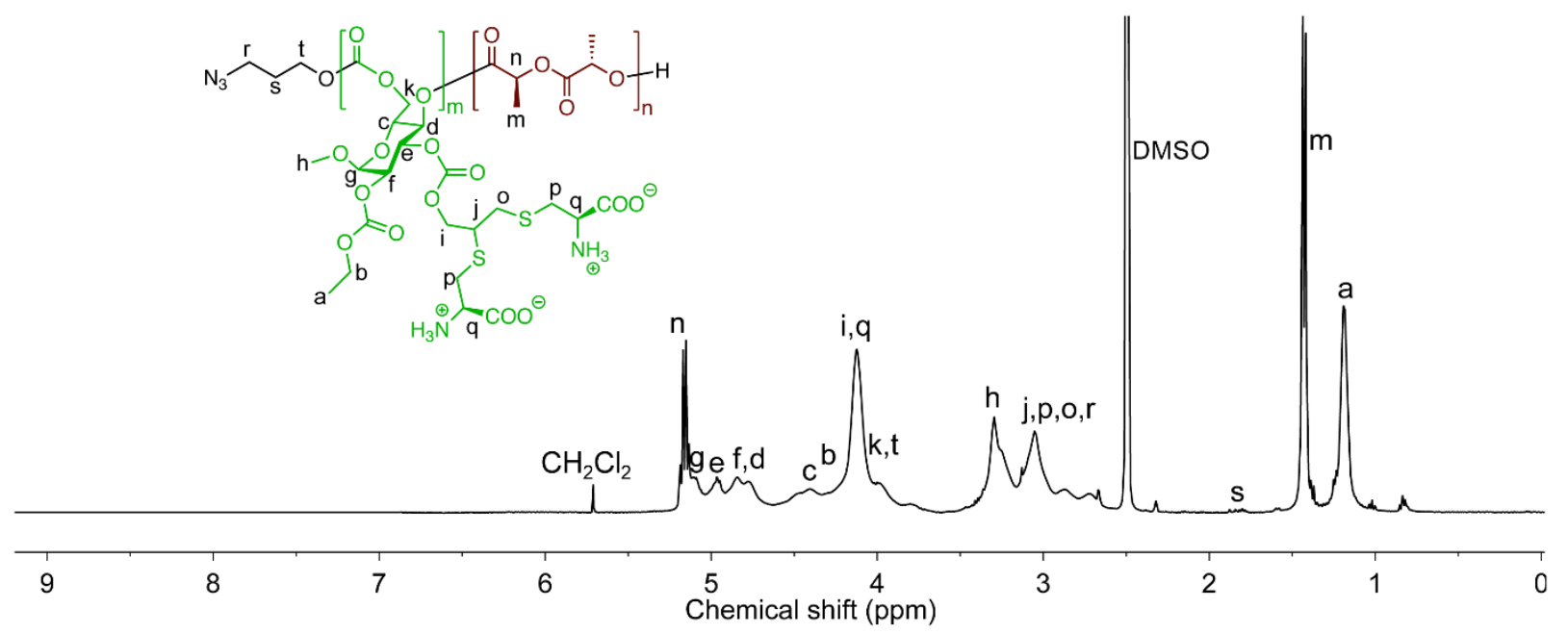

Figure S5. ${ }^{1} \mathrm{H}$ NMR (500 MHz, DMSO- $\left.d_{6}\right)$ spectrum of 2, N3-PDGC(cys)-b-PLLA. 
${ }^{1} \mathrm{H}$ NMR (DMSO- $\left.d_{6}, 500 \mathrm{MHz}\right)$

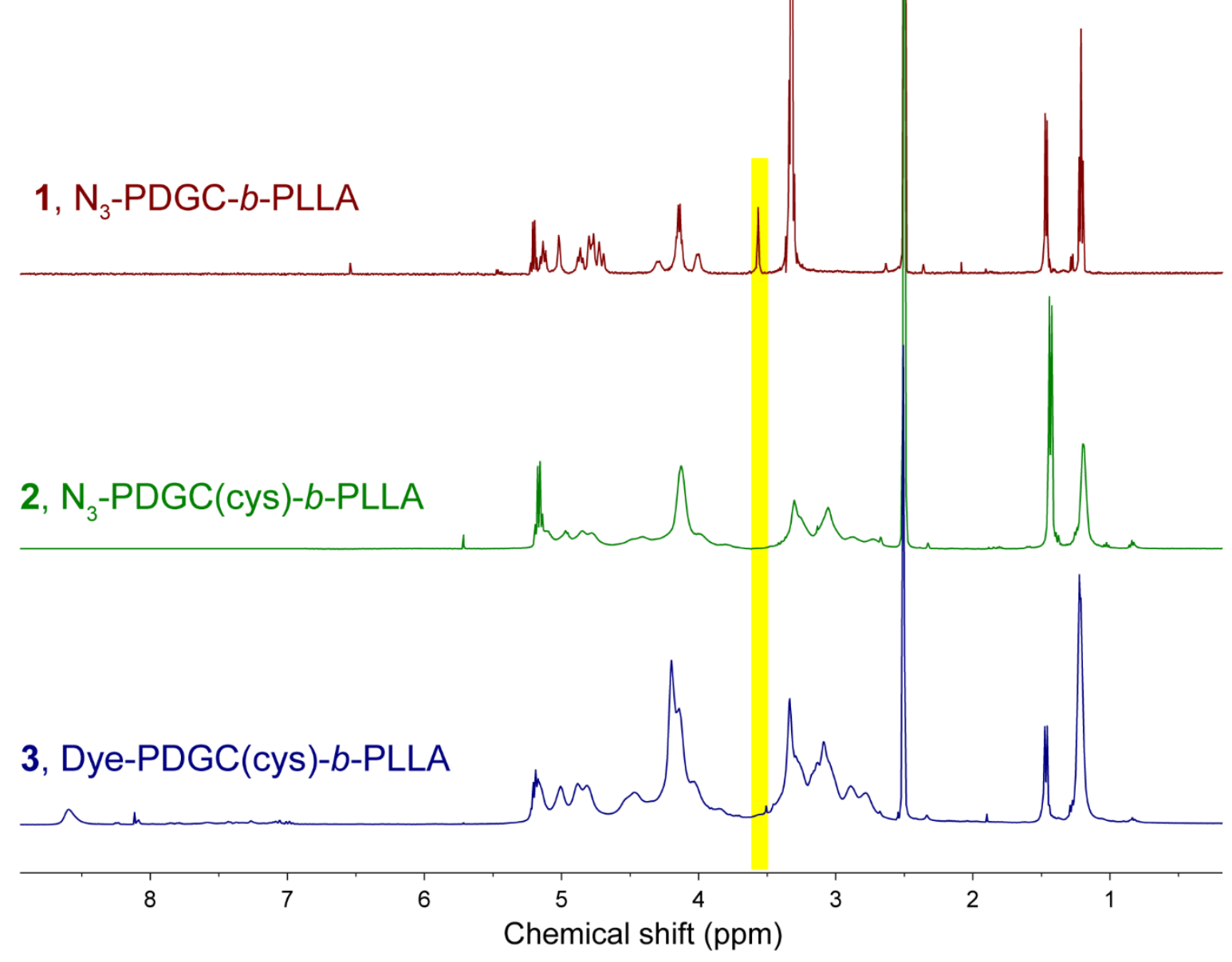

Figure S6. ${ }^{1} \mathrm{H}$ NMR (500 MHz, DMSO- $d_{6}$ ) spectra of polymers $1, \mathrm{~N}_{3}$-PDGC-b-PLLA, 2, N3-PDGC(cys)-bPLLA, and 3, dye-PDGC(cys)-b-PLLA. The highlighted region showed the disappearance of PDGC alkyne proton resonance from 1 after thiol-yne reaction. 


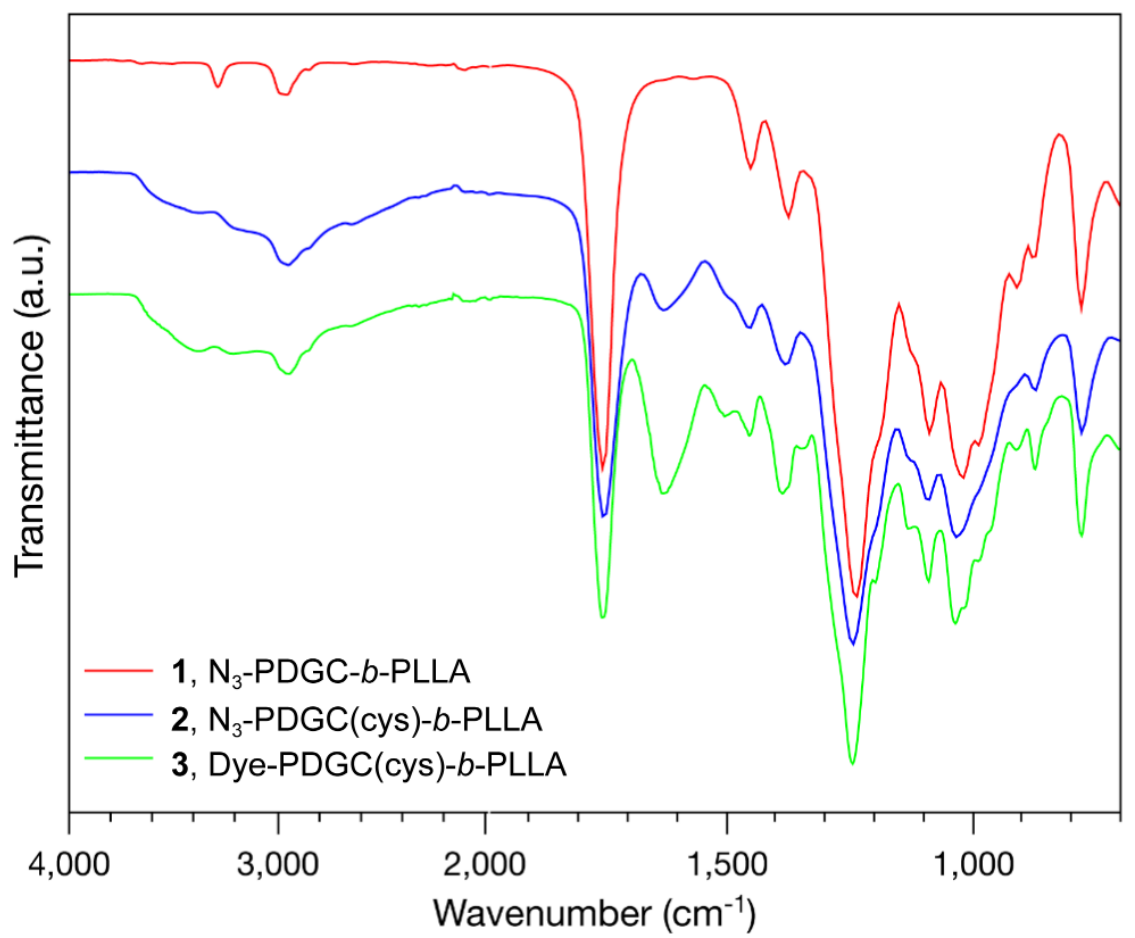

Figure S7. FT-IR spectra of polymers 1, N3-PDGC-b-PLLA, 2, N3-PDGC(cys)-b-PLLA, and 3, dyePDGC(cys)-b-PLLA.

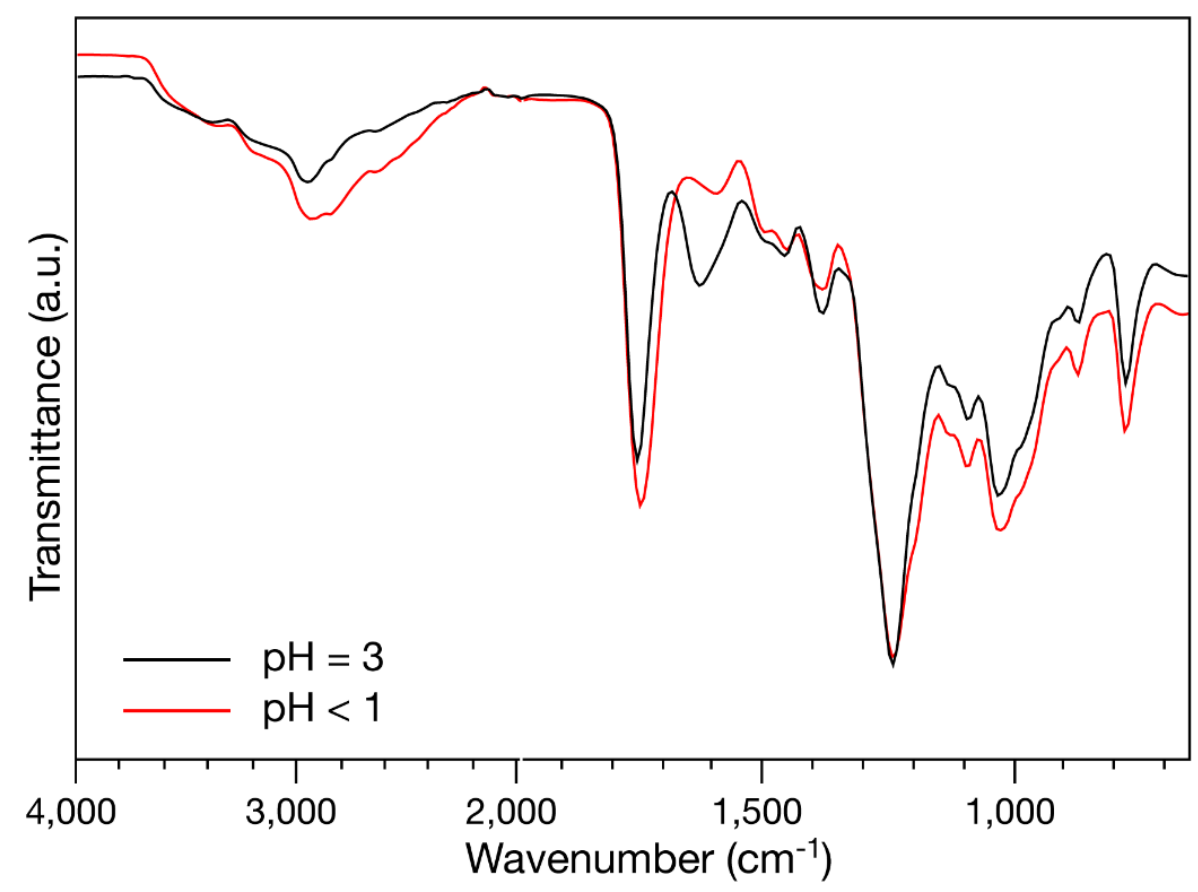

Figure S8. FT-IR spectra of polymer 2 powders prepared by lyophilization from solutions of $\mathrm{pH}=3$ and $\mathrm{pH}$ $<1$. 


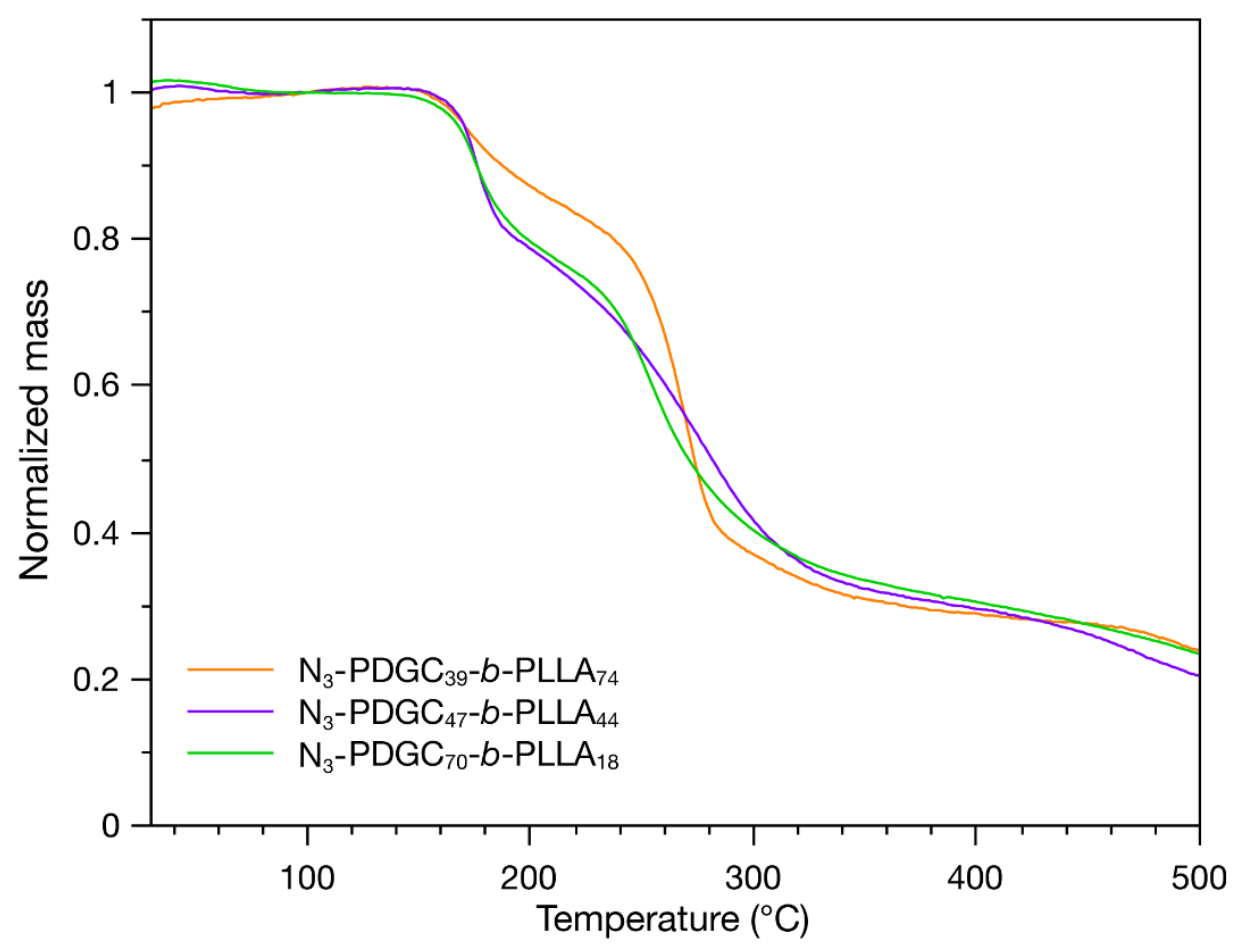

Figure S9. TGA traces $\left(25-500^{\circ} \mathrm{C}, 10^{\circ} \mathrm{C} / \mathrm{min}\right)$ of the series of three $\mathrm{N}_{3}$-PDGC(cys)-b-PLLA block copolymers. 


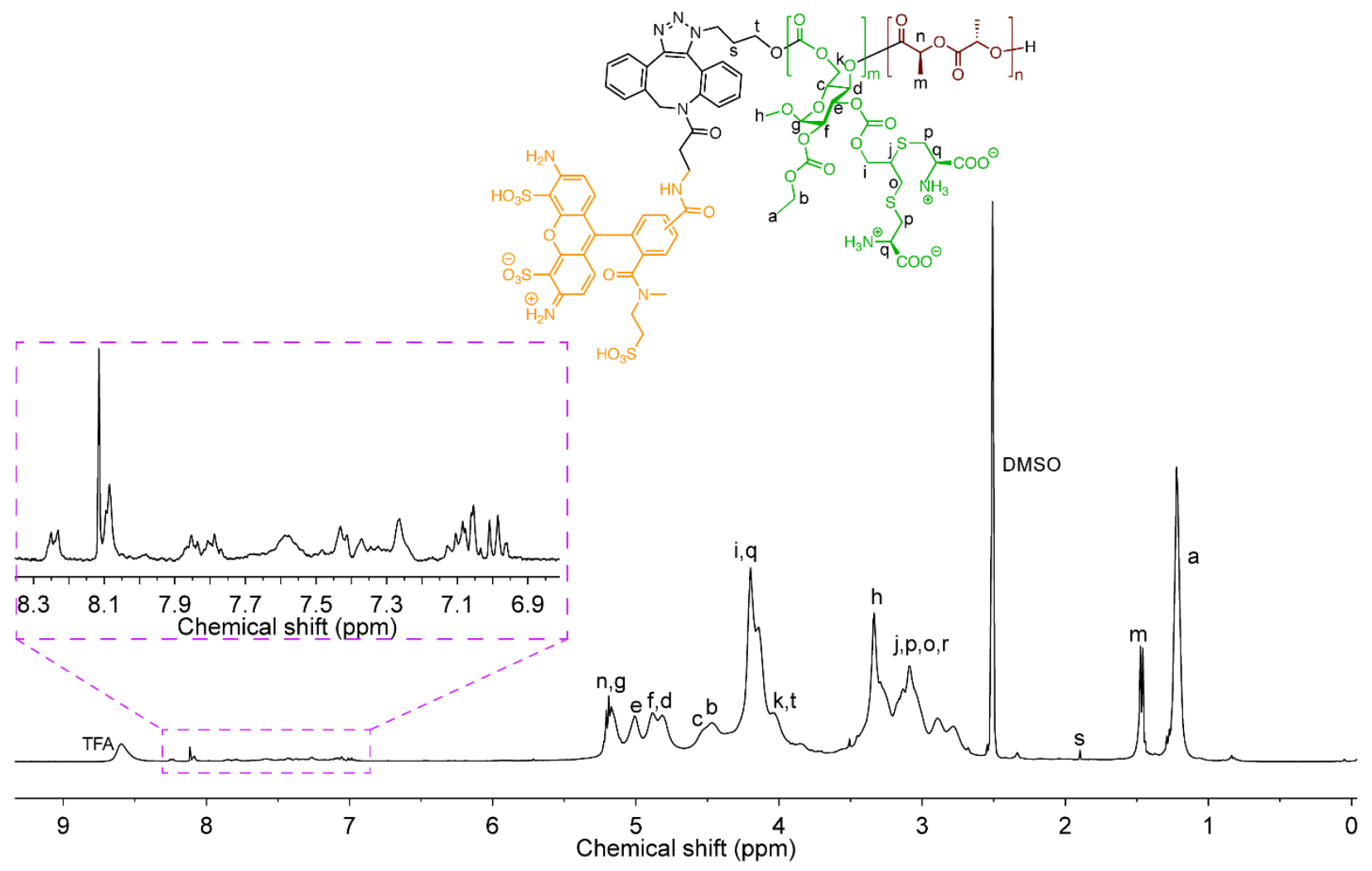

Figure S10. ${ }^{1} \mathrm{H}$ NMR spectrum (500 MHz, DMSO- $d_{6}+$ TFA-d) of Polymer 3. 

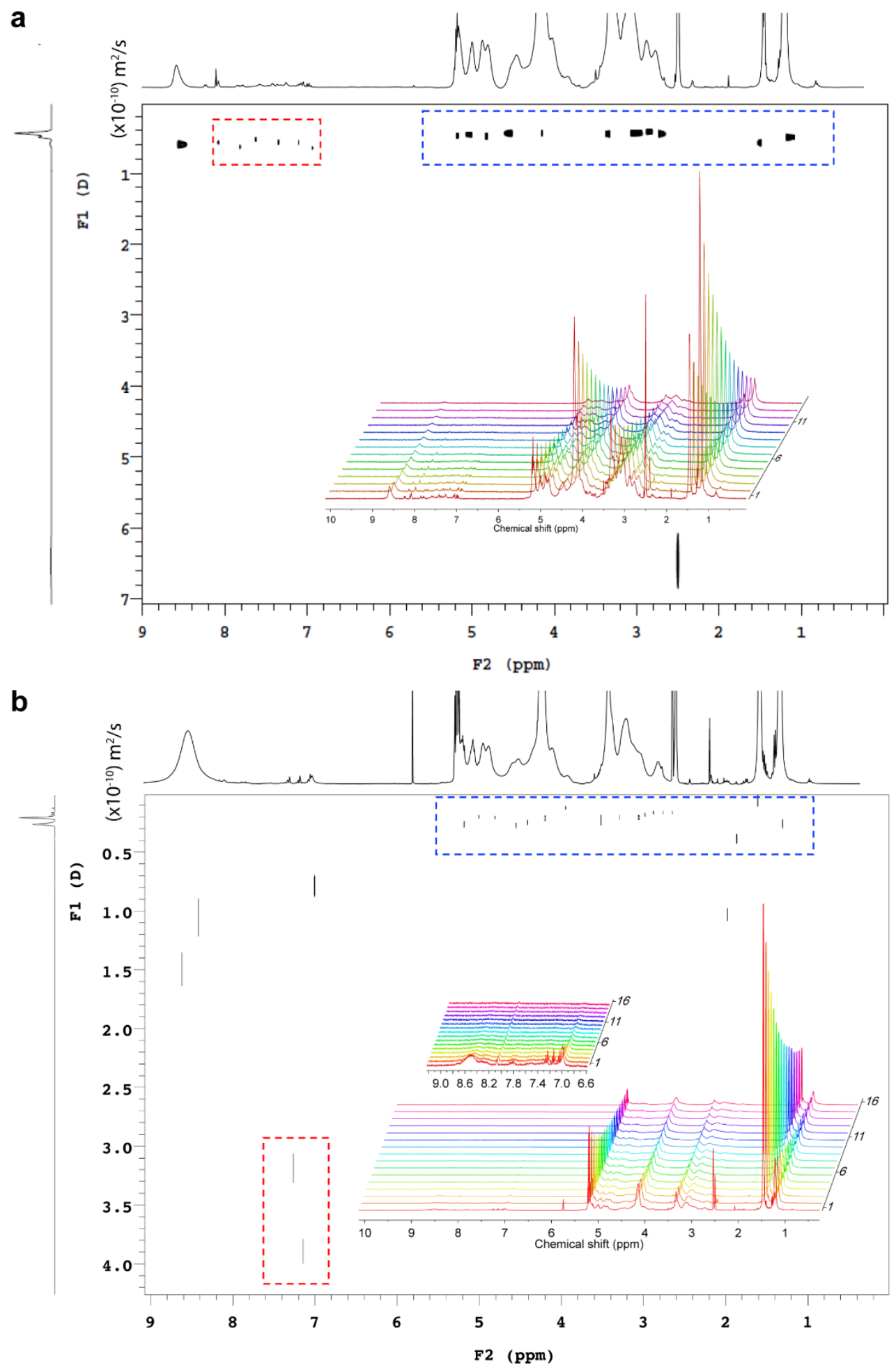

Figure S11. DOSY NMR spectra (500 MHz, DMSO- $d_{6}$, TFA- $d$ ) of (a) dye-polymer conjugate, and (b) dye and polymer mixture. 

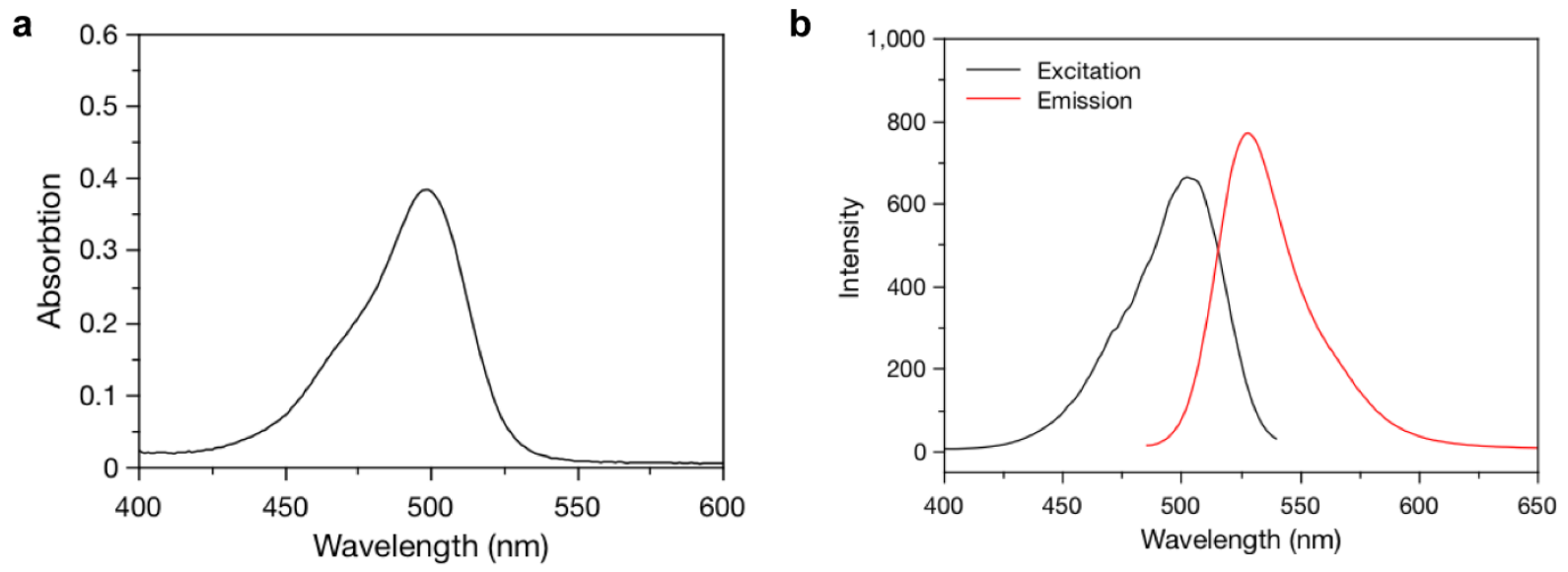

Figure S12. (a) UV-Vis spectrum of dye-polymer conjugate $(0.25 \mathrm{mg} / \mathrm{mL}$ in water). (b) Excitation and emission spectra of dye-polymer conjugate $\left(\lambda_{\mathrm{ex}, \max }=501 \mathrm{~nm}, \lambda_{\mathrm{em}, \max }=528 \mathrm{~nm}\right)$.
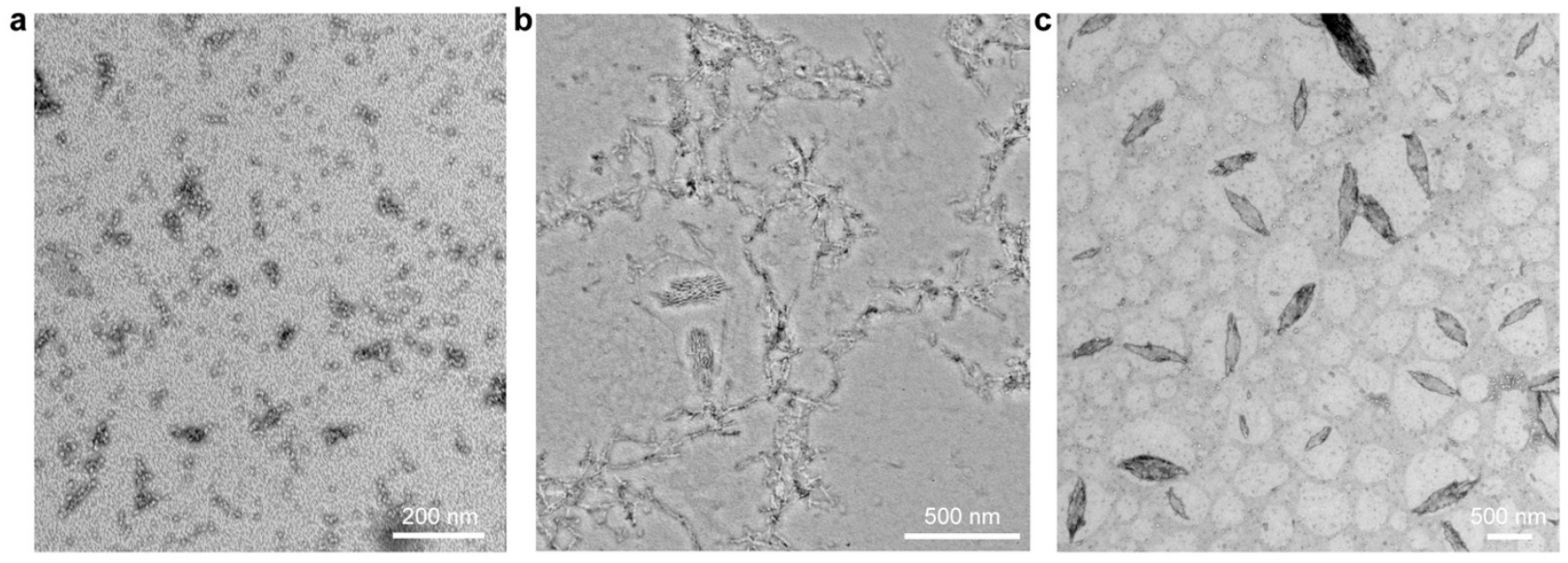

Figure S13. TEM images of nanostructures assembled from (a) dye-PDGC(cys) $70-b-P L L A_{18}$, (b) dyePDGC(cys) $47-b-$ PLLA $_{44}$, and (c) dye-PDGC(cys) ${ }_{39}-b$-PLLA 74. 
a

Anionic diblock copolymer:

$\mathrm{N}_{3}-\mathrm{PDGC}(\mathrm{COOH})_{47}-b-\mathrm{PLLA}_{44}$

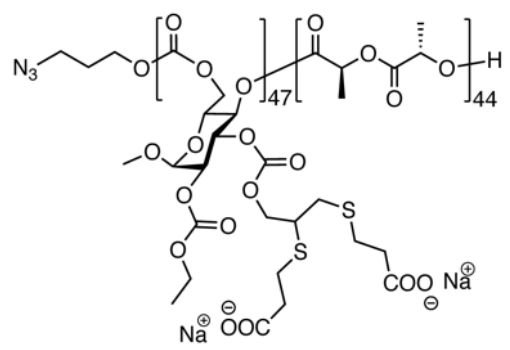

C

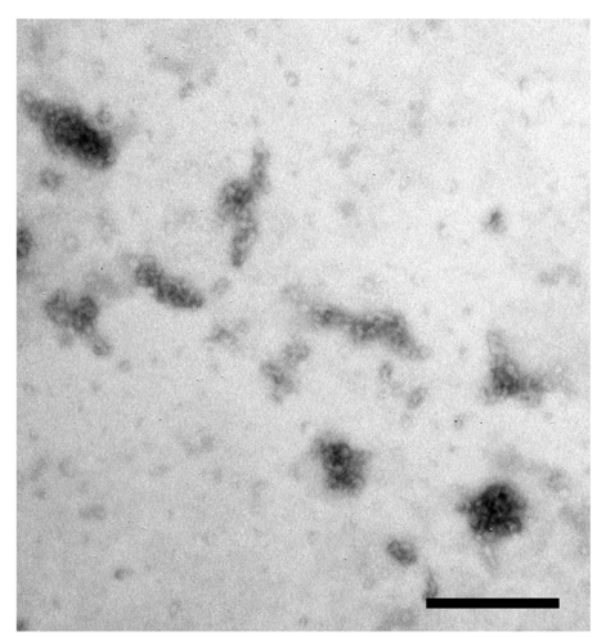

b Neutral diblock copolymer:

$\mathrm{N}_{3}-\left[\mathrm{PDGC}(\mathrm{PEG})_{28}-\mathrm{CO}^{-P D G C} \mathrm{C}_{19}\right]-b-\mathrm{PLLA}_{44}$

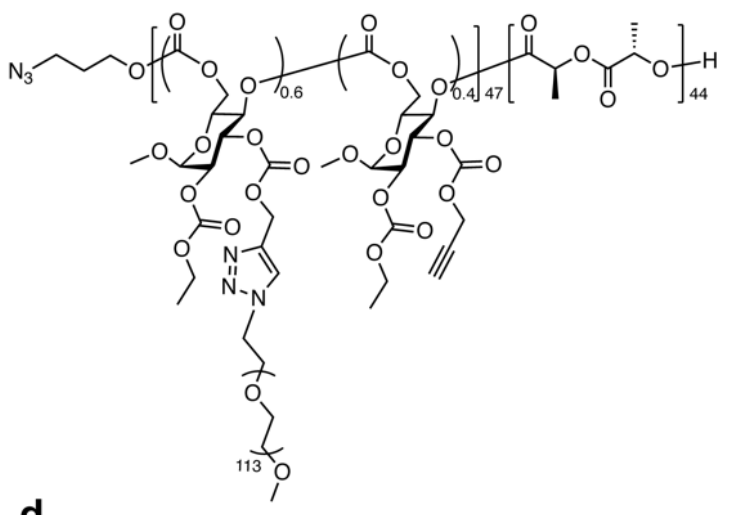

d

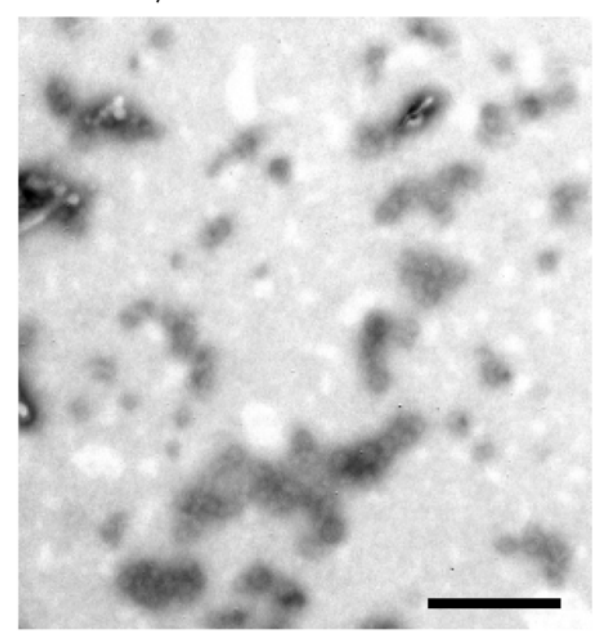

Figure S14. Structures of (a) carboxylic acid-modified $\mathrm{N}_{3}-\mathrm{PDGC}(\mathrm{COOH})-b-\mathrm{PLLA}$, and (b) neutral $\mathrm{N}_{3}-$ PDGC(PEG)-b-PLLA diblock copolymers. TEM images of $c$, anionic micelles (Dav $=12 \pm 2 \mathrm{~nm}$ ) and d, neutral micelles (Dav $=22 \pm 4 \mathrm{~nm}$ ). TEM stained with 1\% PTA; scale bars, $200 \mathrm{~nm}$. 
a
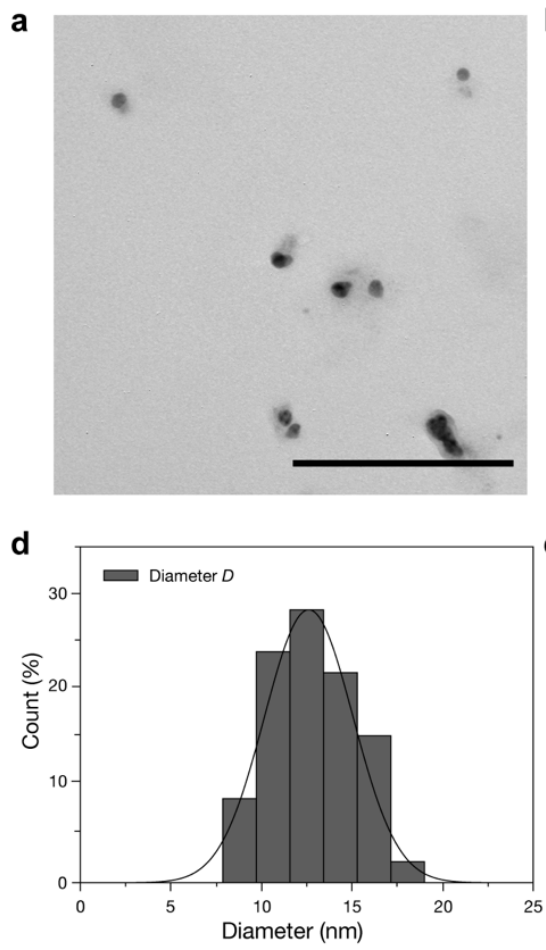

b
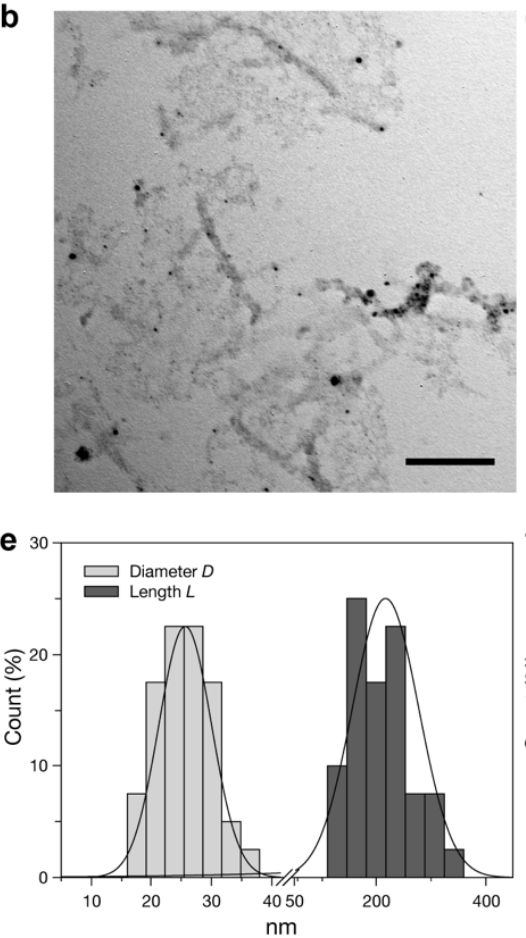

c
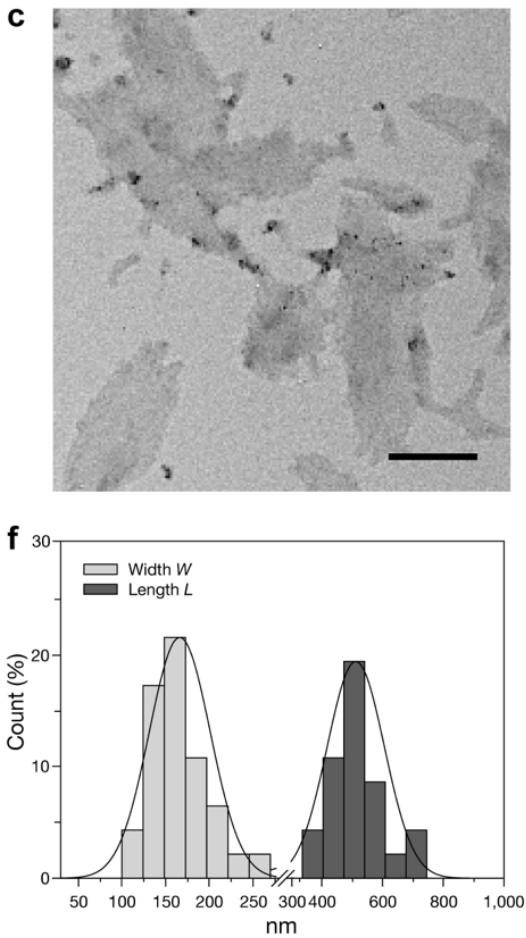

Figure S15. TEM images ( $a, b, c)$ and histograms (d, e, f) of silver-bearing nanostructures of spherical (a, e; $D_{\mathrm{av}}=13 \pm 2 \mathrm{~nm}$ ), cylindrical (b, e; $L_{\mathrm{av}}=210 \pm 60 \mathrm{~nm}, D_{\mathrm{av}}=25 \pm 4 \mathrm{~nm}$ ), and platelet-like (c, f; $L_{\mathrm{av}}=515 \pm$ $102 \mathrm{~nm}, W_{\mathrm{av}}=166 \pm 35 \mathrm{~nm}$ ) morphologies. No stain for TEM samples; scale bars, $200 \mathrm{~nm}$. Data were reported as mean \pm s.d. from measurement of ca. 30 particles

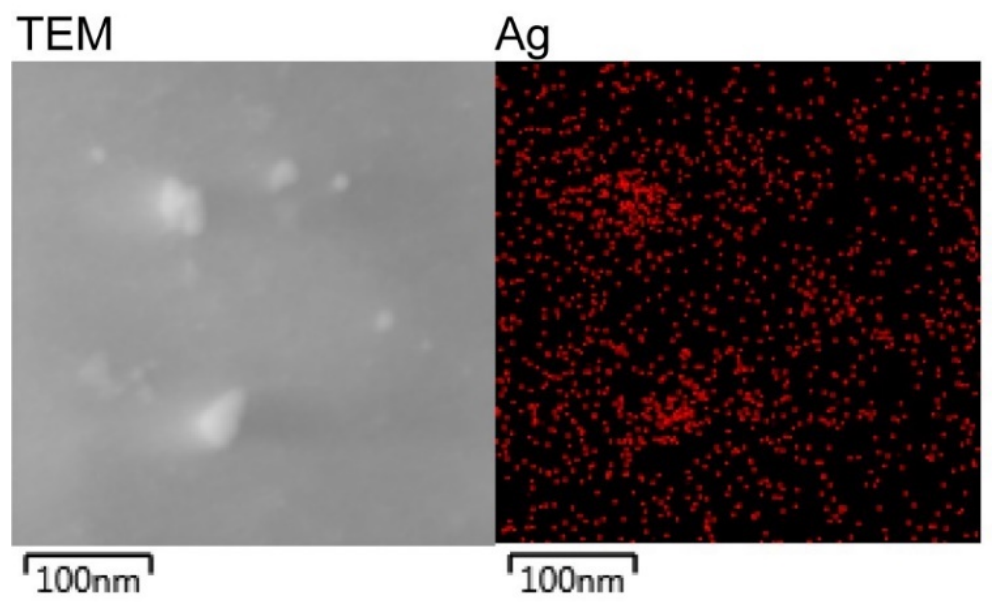

Figure S16. Elemental mapping images of Ag-loaded spherical micelles. 